OPEN ACCESS

Edited by:

Eva Mittler,

Albert Einstein College of Medicine,

United States

Reviewed by:

Jérôme Bouchet,

Université Paris Descartes, France

Marc Kvansakul,

La Trobe Institute for Molecular

Science, La Trobe University, Australia

*Correspondence:

Célia Caillet-Saguy

celia.caillet-saguy@pasteur.fr

tThese authors have contributed equally to this work and share first

authorship

¥ These authors have contributed equally to this work and share last authorship

Specialty section:

This article was submitted to

Virology,

a section of the journal

Frontiers in Microbiology

Received: 04 December 2021

Accepted: 06 January 2022

Published: 23 February 2022

Citation

Zhu Y, Alvarez F, Wolff $N$,

Mechaly A, Brûlé S, Neitthoffer B,

Etienne-Manneville $S$, Haouz A,

Boëda B and Caillet-Saguy C (2022)

Interactions of Severe Acute

Respiratory Syndrome Coronavirus 2

Protein E With Cell Junctions

and Polarity

PSD-95/D/g/ZO-1-Containing

Proteins. Front. Microbiol. 13:829094.

doi: 10.3389/fmicb.2022.829094

\section{Interactions of Severe Acute} Respiratory Syndrome Coronavirus 2 Protein E With Cell Junctions and Polarity

\section{PSD-95/Dlg/ZO-1-Containing Proteins}

\author{
Yanlei Zhu't, Flavio Alvarez ${ }^{1+}$, Nicolas Wolff1, Ariel Mechaly², Sébastien Brûlé \\ Benoit Neitthoffer ${ }^{4}$, Sandrine Etienne-Manneville ${ }^{4}$, Ahmed Haouz $^{2}$, Batiste Boëda ${ }^{4 \neq}$ and \\ Célia Caillet-Saguy ${ }^{1 * \neq}$ \\ ${ }^{1}$ Channel Receptors Unit, CNRS, UMR 3571, Institut Pasteur, Université de Paris, Paris, France, ${ }^{2}$ Crystallography \\ Platform-C2RT, CNRS, UMR 3528, Institut Pasteur, Université de Paris, Paris, France, ${ }^{3}$ Molecular Biophysics \\ Platform-C2RT, CNRS, UMR 3528, Institut Pasteur, Université de Paris, Paris, France, ${ }^{4}$ Cell Polarity, Migration and Cancer \\ Unit, Institut Pasteur, UMR 3691 CNRS, Université de Paris, Equipe Labellisée Ligue Contre le Cancer, Paris, France
}

The C-terminus of the severe acute respiratory syndrome coronavirus 2 (SARS-CoV2) protein E contains a PBM (PDZ-binding motif) targeting PDZ (PSD-95/Dlg/ZO-1) domains, which is identical to the PBM of SARS-CoV. The latter is involved in the pathogenicity of the virus. Recently, we identified 10 human PDZ-containing proteins showing significant interactions with SARS-CoV-2 protein E PBM. We selected several of them involved in cellular junctions and cell polarity (TJP1, PARD3, MLLT4, and LNX2) and MPP5/PALS1 previously shown to interact with SARS-CoV E PBM. Targeting cellular junctions and polarity components is a common strategy by viruses to hijack cell machinery to their advantage. In this study, we showed that these host PDZ domains TJP1, PARD3, MLLT4, LNX2, and MPP5/PALS1 interact in a PBM-dependent manner in vitro and colocalize with the full-length $\mathrm{E}$ protein in cellulo, sequestrating the PDZ domains to the Golgi compartment. We solved three crystal structures of complexes between human LNX2, MLLT4, and MPP5 PDZs and SARS-CoV-2 E PBM highlighting its binding preferences for several cellular targets. Finally, we showed different affinities for the PDZ domains with the original SARS-CoV-2 C-terminal sequence containing the PBM and the one of the beta variant that contains a mutation close to the PBM. The acquired mutations in the E protein localized near the PBM might have important effects both on the structure and the ion-channel activity of the $E$ protein and on the host machinery targeted by the variants during the infection.

Keywords: SARS-CoV-2, envelope protein, host-pathogen interactions, PDZ-binding motif, PDZ-containing protein, protein-protein interaction, cell junctions and polarity 


\section{INTRODUCTION}

Currently, there have been more than 263 million individuals infected by SARS-CoV-2, including more than 5.2 million deaths. ${ }^{1}$ While significant constant advances are made in understanding this virus, the knowledge of the SARS-CoV-2 protein interactions with host cell proteins is still limited.

Targeting multiple cellular PDZ (PSD-95/Dlg/ZO-1)containing proteins through short linear PDZ-binding motifs (PBMs) is a common strategy used by viruses to facilitate their viral replication and dissemination to new hosts (Javier and Rice, 2011). Indeed, PDZ proteins are involved in processes of particular interest in viral infection: cell junction formation, cell polarity establishment, and immune system signaling (Javier and Rice, 2011; James and Roberts, 2016; Gutiérrez-González and Santos-Mendoza, 2019). The two SARS-CoV-2 viroporins, proteins $\mathrm{E}$ and $3 \mathrm{a}$, contain a $\mathrm{C}$-terminal PBM targeting specific PDZ domain-containing proteins (Castaño-Rodriguez et al., 2018; Caillet-Saguy et al., 2021).

PDZ domains are a large family of protein-protein interaction domains widespread in the human proteome (Luck et al., 2012). $\mathrm{PBMs}$ are mainly located at the $\mathrm{C}$-terminus of target proteins and interact directly with PDZ domains. They are classified into three types: type I PBM (-X-S/T-X- $\left.\phi_{\mathrm{COOH}}\right)$, type II PBM (-X- $\phi-\mathrm{X}-$ $\left.\phi_{\mathrm{COOH}}\right)$, and type III PBM (-X-D/E-X- $\left.\phi_{\mathrm{COOH}}\right)$, with $\phi$ signifying a hydrophobic residue. The $\mathrm{C}$-terminal PBM sequence of SARS$\mathrm{CoV}$ E protein is of type II (-DLLV $\mathrm{COOH})$ and has been identified as a virulence factor (Jimenez-Guardeño et al., 2014). It is likely that the abilities to target PDZ proteins also make significant contributions to the pathogenesis of the E protein of SARS$\mathrm{CoV}-2$. Indeed, the E protein is highly conserved with $94.7 \%$ identity between SARS-CoV and SARS-CoV-2, and their PBMs are strictly conserved.

Protein E is a small transmembrane protein of 75 residues involved in several phases of the virus life cycle, such as assembly, budding, envelope formation, and pathogenesis (Schoeman and Fielding, 2019). Protein E has a hydrophobic helical transmembrane domain of 30 residues flanked by an $\mathrm{N}$-terminal domain of 8 residues and a C-terminal domain of 37 residues (Figure 1A; Mandala et al., 2020). It is present in virions in small quantities, whereas it is very abundant in infected cells at the level of the intermediate compartment between the Golgi and the endoplasmic reticulum (ERGIC) where its expression increases the $\mathrm{pH}$ inside the organelle (Cabrera-Garcia et al., 2021). Protein E actively participates in the budding, morphogenesis, and trafficking of the virus. A cytoplasmic orientation of the C-terminal domain and a luminal orientation for the $\mathrm{N}$-terminal domain has been reported (Nieto-Torres et al., 2011; Duart et al., 2020). The E protein can oligomerize via its transmembrane domain into a homopentameric ion channel called viroporin that inserts into the host cell endomembrane system (Li et al., 2014) possibly modulated by changes in $\mathrm{pH}$ (Cabrera-Garcia et al., 2021). Recently, the pentameric structure of the transmembrane domain within a lipid bilayer reconstituting the ERGIC membrane has

${ }^{1}$ https://covid19.who.int/ been reported by NMR in the absence of the cytoplasmic part (Mandala et al., 2020). The C-terminal cytoplasmic part of protein $\mathrm{E}$ is important for interactions with different partners such as its PBM sequence to interact with PDZcontaining proteins.

Previously, we used a high-throughput quantitative approach using a library covering all the human PDZ domains (Vincentelli et al., 2015) to establish the list of PDZ-containing proteins potentially targeted by SARS-CoV-2 E protein through its PBM. Among the $10 \mathrm{PDZ}$-containing proteins identified, four are involved in cellular junction and polarity: ZO-1 (also called TJP1), LNX2, PARD3, and MLLT4 (also called Afadin) (CailletSaguy et al., 2021; Table 1).

Indeed, ZO-1 is one of the essential proteins that connect transmembrane tight-junction proteins to the actin cytoskeleton. It consists of three PDZ domains, the second being the one that has a high affinity for the PBM motif of the E protein of SARS-CoV-2 (Caillet-Saguy et al., 2021; Shepley-McTaggart et al., 2021). Robinot et al. (2021) reported a disruption of the epithelial barrier integrity and an alteration of the $\mathrm{ZO}-1$ distribution at the tight junctions (TJs) during infection with SARS-CoV-2. LNX2 acts as a molecular scaffold for Numb family proteins, essential players in the regulation of cell adhesion and polarity (Wang et al., 2009). PARD3 is an essential protein in asymmetric cell division and in polarized growth. It plays a central role in the establishment of TJs (Chen et al., 2017). MLLT4 is an adapter protein linking nectin to the actin cytoskeleton, essential for the formation of adherent junctions and the regulation of cell adhesion (Ikeda et al., 1999). In addition, the $\mathrm{E}$ protein of SARS-CoV was previously reported to interact with the PDZ-containing protein MPP5 (also called PALS1) through PBM-PDZ interaction altering TJ formation and the mammalian epithelium structure (Teoh et al., 2010). A recent study reported that the $\mathrm{E}$ protein $\mathrm{PBM}$ recognizes a pocket formed by residues from the PDZ and SH3 domains of MPP5 (Chai et al., 2021). As a key component of the Crumbs complex that controls the apical-basal polarity and TJ formation (Roh et al., 2002), MPP5 may contribute to the lung epithelium breakdown observed in patients infected by SARS-CoV. The relevance of these five $\mathrm{PBM} / \mathrm{PDZ}$ interactions is not yet fully understood. Understanding the pathogenicity of this virus is currently a global health issue and targeting these virus-host interactions could reduce damage to the respiratory tract barrier and moderate the virus spread.

In this study, we showed that these five PDZ domains interact in vitro with the full-length $\mathrm{E}$ protein in a PBM-dependent manner and colocalize with the full-length E protein in cellulo, sequestrating the PDZ domains to the Golgi compartment. We further solved the three crystal structures of human PDZ/SARS-CoV-2 E PBM complexes for LNX2, MLLT4, and MPP5, highlighting their specific binding modes (Table 1). A mutation in the E protein localized near the PBM (P71L) was reported in the variant of concern (VOC) beta (B.1.351) (Figure 1B). We showed here different affinities between the PDZ domains and the SARS-CoV-2 WT and the beta variant E C-terminals encompassing the PBM (Figure 1C). Thus, the acquired mutations might have important consequences on 


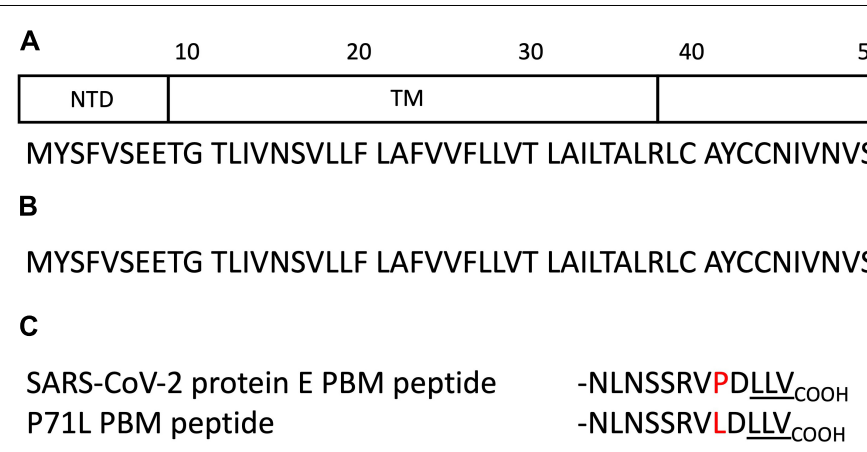

FIGURE 1 | Schematic domain representation and sequences of the protein E constructs. (A) Domain delimitations and sequence of the full-length protein E of SARS-CoV-2. NTD, TM, and CTD correspond to the N-terminal domain, the transmembrane domain, and the C-terminal domain respectively. (B) Sequence of the full-length protein E of SARS-CoV-2 beta variant (B.1.351). (C) Sequences of the SARS-CoV-2 WT and the beta variant E C-terminal encompassing the PSD-95/Dlg/ZO-1-binding motif (PBM). The PBMs are underlined. The mutation is highlighted in red.

TABLE 1 | Selected human PSD-95/Dlg/ZO-1 (PDZ) domains targeted by the SARS-CoV-2 E protein PSD-95/Dlg/ZO-1-binding motif (PBM).

\begin{tabular}{|c|c|c|c|c|}
\hline PDZ domain & Uniprot & Delimitations & PDB structure/alphafold model & $\alpha 2$ residue facing $p-2$ \\
\hline ZO-1 PDZ2 & Q07157 & $184-264$ & 2JWE & Leu \\
\hline LNX2 PDZ2 & Q8N448 & $334-426$ & 7QCT ${ }^{a}$ & Pro \\
\hline PARD3 PDZ3 & Q8TEWO & $582-685$ & Alphafold prediction (Jumper et al., 2021) & Asn \\
\hline MLLT4 & P55196 & 1002-1095 & 7QCR ${ }^{a}$ & Gln \\
\hline MPP5 & Q8N3R9 & 238-336 & 7QCS ${ }^{a}$ & Val \\
\hline
\end{tabular}

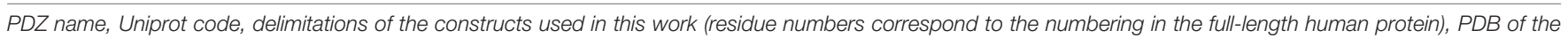
structure model used, and the residue of PDZ helix a2 facing the PBM residue at position -2.

astructure solved in this work.

host machinery targeted during the infection in addition to a potential effect both on the structure and the ion-channel activity of the E protein.

\section{RESULTS}

\section{PDZ Domains of the Proteins Involved in Cell Junctions and Cell Polarity Bind to the Full-Length E Protein in a PBM-Dependent Manner}

We selected five PDZ-containing proteins involved in cellular junction and polarity from our previous high-throughput study on the specificity profile of the C-terminal SARS-CoV-2 E PBM sequence (Figure 1C) against our library of all human PDZ domains (PDZome) using the automated holdup assay (Vincentelli et al., 2015; Duhoo et al., 2019; Caillet-Saguy et al., 2021). These are ZO-1, LNX2, PARD3, MLLT4, and MPP5 previously reported to interact with SARS-CoV-2 E PBM through PBM-PDZ interactions (Table 1).

To investigate whether the five PDZ domains can interact with the full-length $\mathrm{E}$ protein and in a PBM-dependent manner, glutathione S-transferase (GST) pull-down assays were performed with the purified GST-tagged PDZ domains of ZO-1, LNX2, PARD3, MLLT4, and MPP5 and the lysates of HEK293 cells overexpressing constructs of GFP alone, GFPtagged wild-type full-length E protein (GFP-E-WT), GFP-tagged full-length E protein with the PBM mutated with glycines (GFP-E-GGGG), and GFP-tagged cytoplasmic tail of protein E (last 12 residues; GFP-E last 12 aa) designated 1, 2, 3, and 4 in Figure 2 (Figure 2A). The GFP-tagged construct expression was assessed by examining the fluorescence emitted by the GFP by microscopy and by Western blot on the cell lysates using antiGFP antibody (Figure 2B). GST alone was used as a negative control. We confirmed by using Ponceau S staining that equal amounts of GST-tagged protein constructs were bound to the GST resin (Figure 2C).

Glutathione S-transferase alone and its fusion with PDZ ZO1, PDZ LNX2, PDZ MLLT4, PDZ MPP5, and PDZ PARD3 are used as baits and were immobilized on glutathione beads and tested for their ability to pull down GFP alone, GFPE-WT, GFP-E-GGGG, and GFP-E last 12 aa by Western blot using the anti-GFP antibody. After washing, identical amounts of beads were analyzed for the presence of GFPtagged proteins.

The GFP-E last 12 aa was detected in all interactions with GST-PDZ domains but not detected with GST alone confirming the interactions identified in our high-throughput holdup assay (Caillet-Saguy et al., 2021), validating the interactions within the context of lysates of HEK293 cells overexpressing SARS-CoV-2 protein E constructs (Figure 2C).

GFP-tagged wild-type full-length E protein was also detected in all interactions with GST-PDZ domains but with GST-PDZ PARD3 that showed no clear band (Figure 2C). In all cases, the bands have a weaker intensity than GFP-E last 12 aa in 
A

B
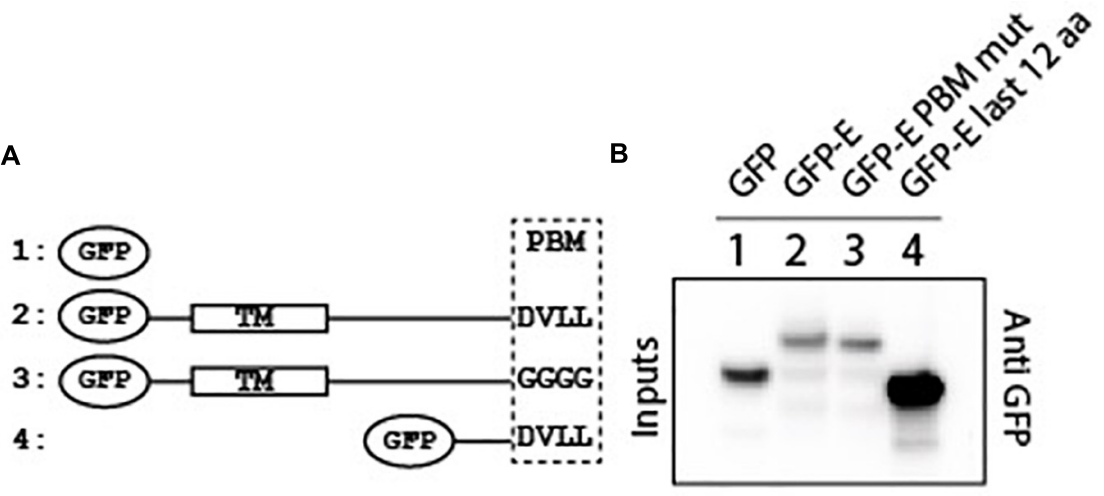

C
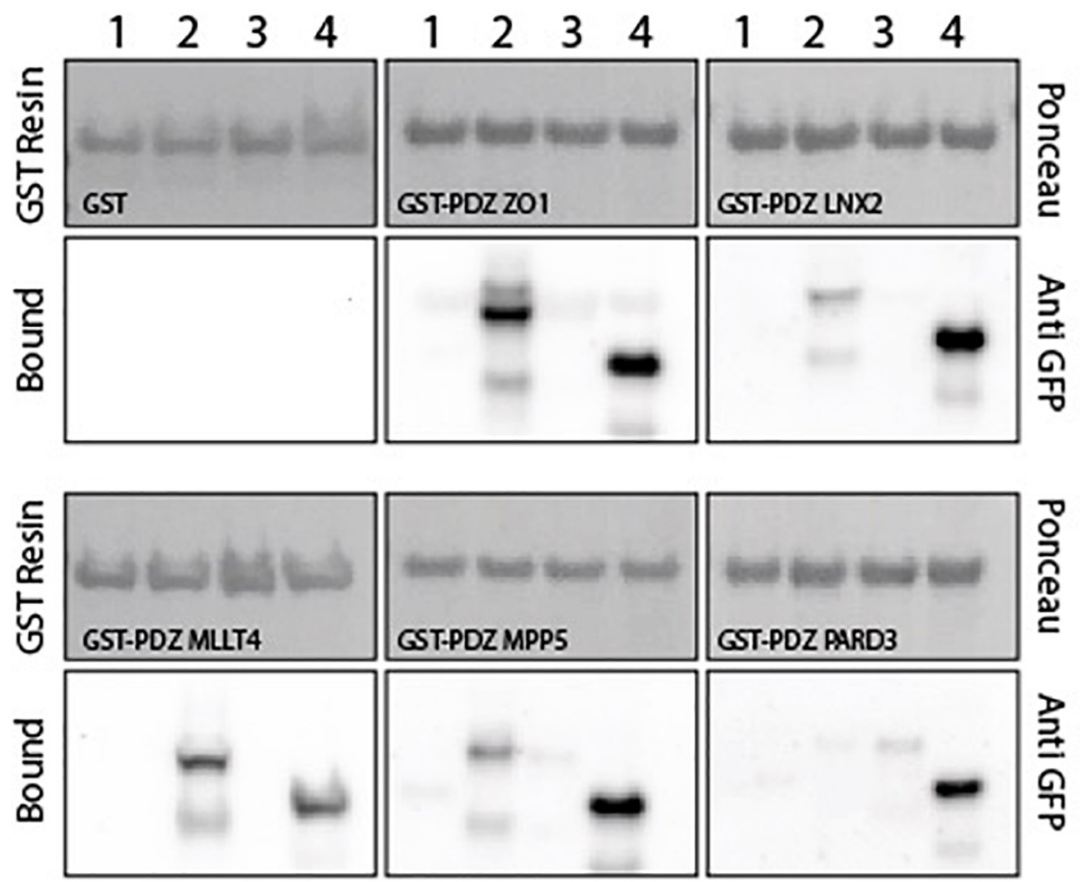

FIGURE 2 | PDZ domains interact with the SARS-CoV-2 full-length E protein in a PBM-dependent manner. (A) Schematic representation of the GFP-E constructs used in this study. Construct 1 corresponds to the GFP alone, construct 2 and 3 to the full-length WT and mutated E protein respectively, and construct 4 to the last $12 \mathrm{C}$-terminal residues of E protein. TM and PBM correspond to the transmembrane domain and to the PDZ-binding motif, respectively. (B) Input fraction of GFP-tagged viral E gene construct expressed in HEK293 cells and used for pull-down assay. Samples were analyzed by immunoblotting using anti-GFP antibody. (C) Gluthatione S-transferase (GST) pull-down binding results with immobilized GST or GST-PDZ domains (GST-PDZ ZO1, GST-PDZ LNX2, GST-PDZ MLLT4, GST-PDZ MPP5, and GST-PDZ PARD3) used as affinity resin and incubated with the HEK293 cell lysates. GST-tagged proteins were stained by Ponceau S (top panels). The bound fraction was analyzed by immunoblotting using an anti-GFP antibody (bottom panels). Note that blots represent discontinuous panels from the gels when black line delimitation is present. The images have been cropped to frame the relevant region.

agreement with a significant lower expression in cells, as shown in the inputs for GFP-E-WT compared with GFP-E last 12 aa (Figure 2B). We failed to obtain a clear detection of the band for GST-PDZ PARD3 (Figure 2C). Conversely, GFP-EGGGG was not detected in all interactions with GST-PDZ domains except with GST-PDZ PARD3 that showed a weak band (Figure 2C).

Altogether, these results indicate a specific interaction between the SARS-CoV-2 WT protein E and the PDZ domains of ZO-1, LNX2, MLLT4, and MPP5 with variations in binding intensities except for PARD3. These interactions are PBM dependent in the context of the full-length E protein.

\section{Structures of Complexes Between PDZ Domains of MLLT4, MPP5, and LNX2 and the C-Terminal of Protein E}

We deciphered the molecular basis of recognition of the C-terminal sequence of the protein $\mathrm{E}$ of SARS-CoV-2 encompassing the PBM by the PDZ domains of the proteins 

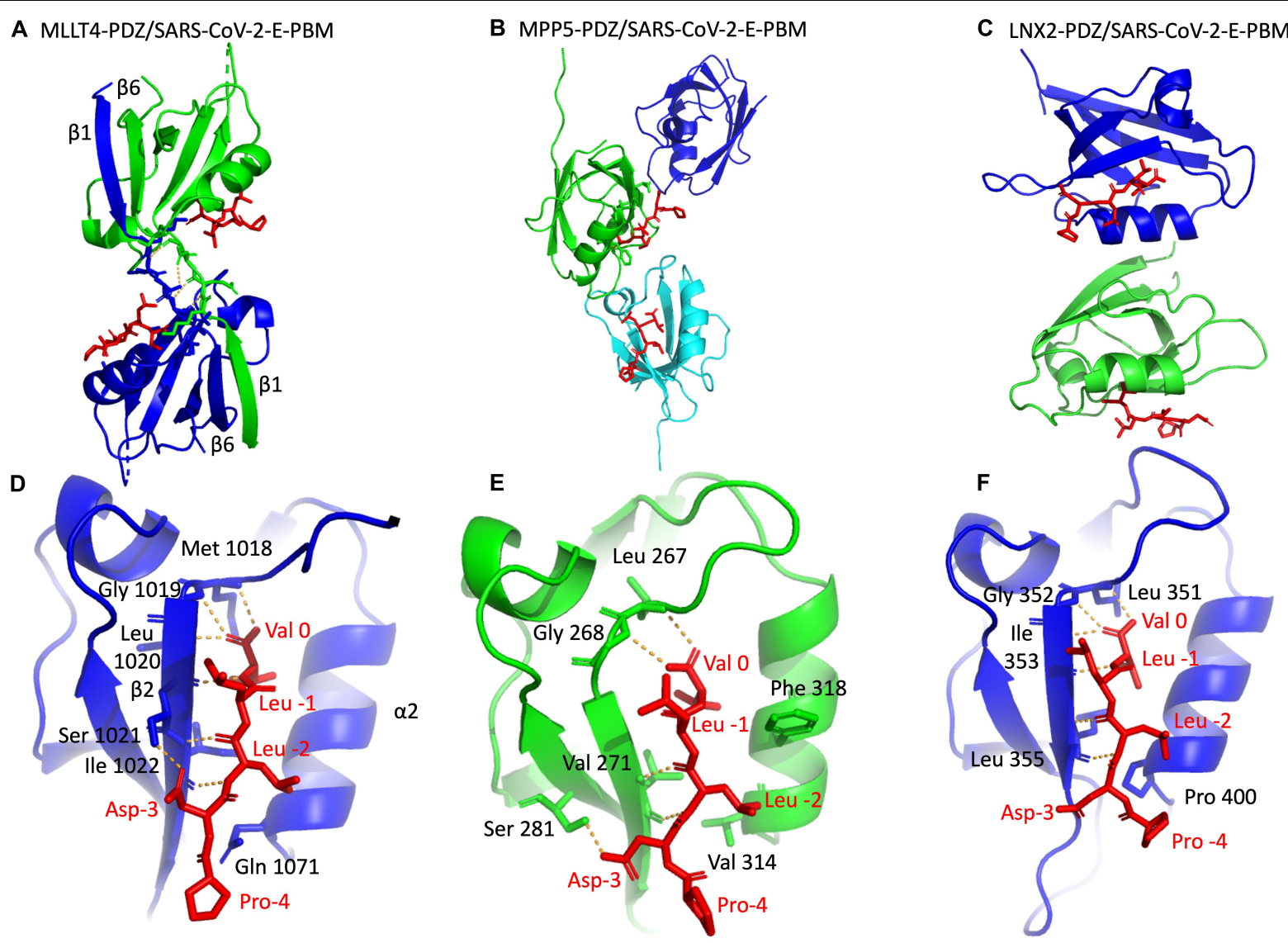

FIGURE 3 |X-ray structures of the PDZ domains of MLLT4, MPP5, and LNX2 bound to the SARS-CoV-2 protein E PBM. (A-C) The asymmetric unit of the PDZ domains of MLLT4, MPP5, and LNX2, respectively, bound to the SARS-CoV-2 protein E PBM shown as red sticks. (A) Selected interchain polar contacts related to the swapped dimer between the fragments Lys 1014-Gly 1017 of each chain are shown in orange, and the associated residues are shown as sticks. (D-F) Detailed views of the PDZ domains bound to SARS-CoV-2 protein E PBM. Important residues are labeled and shown as sticks. Intermolecular H-bonds and polar contacts are reported as orange dashed lines.

engaged in cellular junction and polarity. To this aim, we solved the crystal structures of the complex formed by the C-terminal peptide of protein $\mathrm{E}$ encompassing the PBM (Figure 1C) and the PDZ domains of MLLT4, MPP5, and LNX2 (Table 1) by molecular replacement (Figure 3 and Table 2). We have described the set of intermolecular bonds to gain structural insights into the binding mode of the C-terminal sequence of the protein $\mathrm{E}$ of SARS-CoV-2 with PDZ domains.

\section{Structure of the PDZ Domain of MLLT4 in Complex With the PBM of Protein E}

The crystal structure of MLLT4-PDZ in complex with SARSCoV-2-E-PBM peptide was solved at a resolution of $2.28 \AA$. The final refined model contains two PDZ domains per asymmetric unit that adopt a swapped dimer conformation with the PDZ folding comprising five $\beta$ strands and two $\alpha$ helices. Two peptides are bound to each PDZ dimer (Figure 3A). An electron density is observed for the last five and last three residues of the peptide containing the PBM indicating a well-defined conformation of these last $\mathrm{C}$-terminal residues. The last three residues of the
SARS-CoV-2-E-PBM peptide bind to the $\alpha 2 / \beta 2$-groove in each PDZ unit (Figure 3D).

The swapped dimer comprises an intermolecular interaction between the two PDZ domains through the $\beta 1 / \beta 6$ pair (Figure 3A), and several pairs of inter-domain H-bonds between the fragments Lys 1014-Gly 1017 of each chain (Figure 3A).

The E PBM binds to the PDZ in a conventional manner as an antiparallel extension of the $\beta 2$ strand by inserting into a binding groove formed by the $\beta 2$ strand, the $\alpha 2$ helix, and the "GLGF" motif. The last four residues of the SARSCoV-2-E-PBM peptide were in contact with the PDZ domain, whereas only the last three residues were in contact and the upstream residues were distant from the PDZ domain surface in the previously reported complex between MLLT4-PDZ and the nectin-3 or the Bcr PBM peptides (Chen et al., 2007; Fujiwara et al., 2015).

The C-terminal carboxylate of Val at position 0 of the PBM forms three hydrogen bonds with the amide protons of Met 1018, Gly 1019, and Leu 1020 of the "GLGF" loop of MLLT4PDZ (Figure 3D). A hydrogen bond is also formed between 
TABLE 2 | X-ray data collection and refinement statistics.

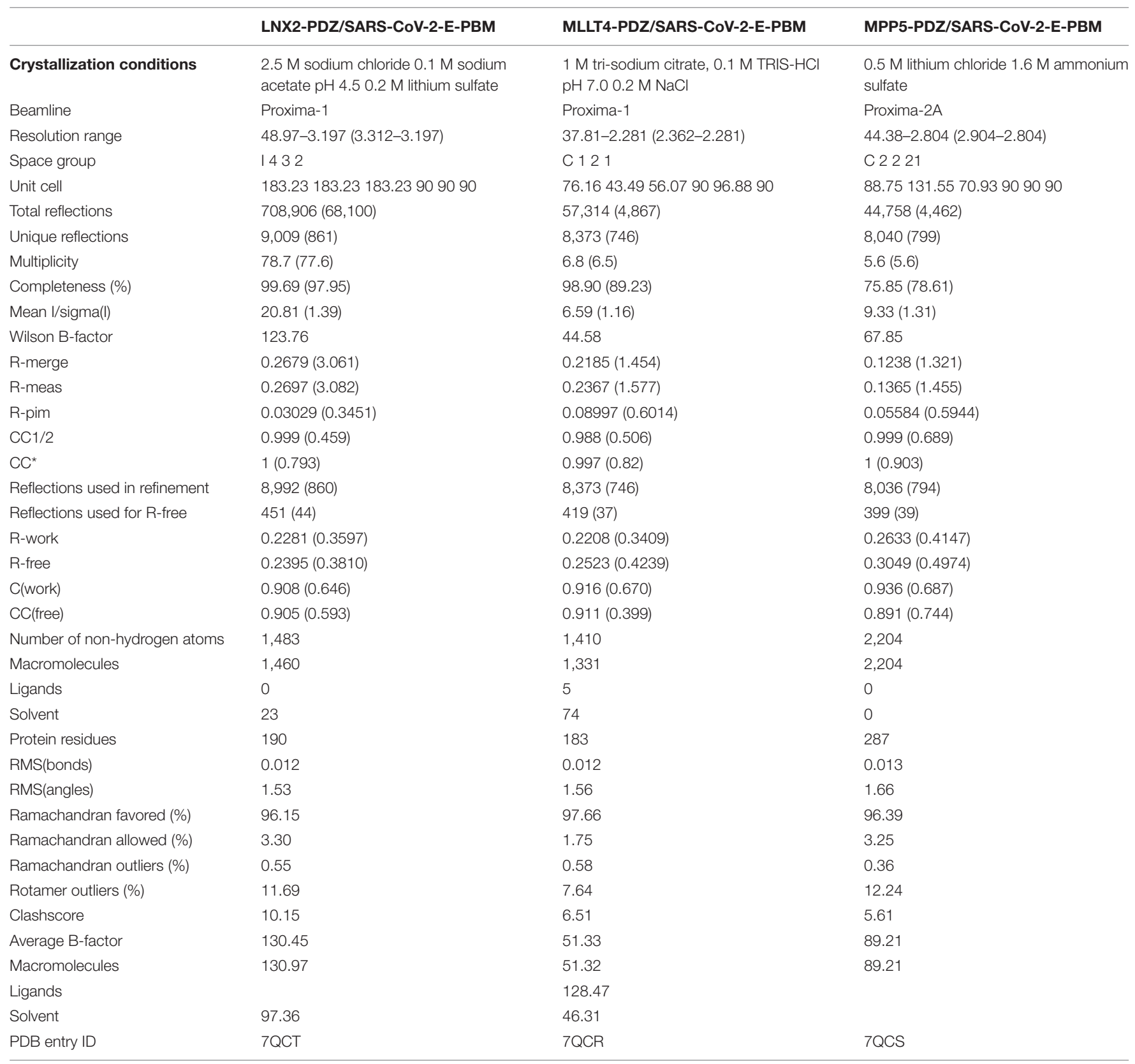

Statistics for the highest-resolution shell are shown in parentheses.

the proton amide of this Val 0 and the carbonyl of Leu 1020 of the $\beta 2$ strand. In addition, the carbonyl and the amide group of Leu at position -2 interacts through a hydrogen bond with the proton amide and the carbonyl group of Ile 1022, respectively. The Ile -2 side chain establish hydrophobic contacts with the side chains of Gln 1071 and Ile 1022. A hydrogen bond is also formed between the carboxyl at the end of the side chain of Asp at position -3 of the PBM and the hydroxyl of Ser 1021 of the $\beta 2$ strand (Figure 3D). Thus, the formed $\beta$ sheet involved the last three residues of the SARS-CoV2 E protein.

\section{Structure of the PDZ Domain of MPP5 in Complex With the PBM of Protein E}

The crystal structure of the MPP5-PDZ in complex with SARS$\mathrm{CoV}-2$-E-PBM was solved at a resolution of $2.80 \AA$. There are three MPP5-PDZs per asymmetric unit (Figure 3B). Each domain adopts a compact globular PDZ fold, and an electron density was observed for the last five residues of the peptide in two MPP5-PDZs present in the asymmetric unit.

As for MLLT4, the E PBM conventionally binds to the MPP5PDZ. The C-terminal carboxylate of the Val at position 0 of the PBM forms two hydrogen bonds: one with the amide proton of 
Leu 267 and one with Gly 268 of the "GLGF" loop of MPP5PDZ (Figure 3E). In addition, the amide and carbonyl groups of Leu at position -2 form hydrogen bonds with the carbonyl and amide proton of valine 271, respectively. Interestingly, as for MLLT4, a hydrogen bond is also formed between the carboxyl at the end of the side chain of Asp at position - 3 of the PBM and the hydroxyl group of Ser 281 of the $\beta 3$ strand (Figure 3E). The key hydrogen bonds of Val 0 and Leu -2 are similar with the structure recently reported (Javorsky et al., 2021). However, the side chains of Asp at position -3 and Arg 272 form an ionic bond within this structure. The alternative hydrogen bond with Ser 281 identified in our structure was previously reported in the complex formed by MPP5-PDZ and the PBM peptide of Crumbs (Javorsky et al., 2021). Furthermore, the side chain of Phe 318 in $\alpha 2$ helix, which prevents access to the binding groove in the unbound form (Ivanova et al., 2015), is located out of the binding groove in our structure allowing SARS-CoV-2-E-PBM peptide binding (Figure 3E) as previously stated for MPP5-PDZ in complex with SARS-CoV-1 E and SARS-CoV-2 E PBMs, as well as for Crumbs peptides (Javorsky et al., 2021).

\section{Structure of the PDZ Domain of LNX2 in Complex With the PBM of Protein E}

The crystal structure of LNX2-PDZ2 in complex with SARSCoV-2-E-PBM was solved at a resolution of $3.3 \AA$. Each of the two LNX2-PDZs present in the asymmetric unit are bound to the peptide (Figure 3C). The PDZ fold agrees with the unbound form of LNX2-PDZ (PDB 5e1y) with an overall RMSD of the backbone atoms of the two PDZs of $0.44 \AA$. Electron density was observed for the last five residues of the two peptides (Figure 3F). In both cases, the last three residues of the SARS-CoV-2-E-PBM peptide bind to the canonical $\alpha 2$ helix/ $\beta 2$ strand groove in each PDZ unit (Figure 3C).

As for MLLT4 and MPP5, the PBM of protein E conventionally binds to the PDZ of LNX2. The C-terminal carboxylate of Val 0 of the PBM forms three hydrogen bonds: two with the amide protons of Leu 351 and Gly 352 of the "GLGF" loop of LNX2-PDZ2 and one with the Ile 353 amide proton (Figure 3F). The proton amide of Val 0 also forms an $\mathrm{H}$-bond with the carbonyl of Ile 353. In addition, the amide and carbonyl groups of Leu -2 form hydrogen bonds with the carbonyl and amide proton of Leu 355, respectively (Figure 3F). In one of the two complexes, an ionic bond is formed between the carboxylate of Val at position -3 of the PBM and the amine group of Arg 357 at the end of the $\beta 2$ strand.

In summary, we have shown that the SARS-CoV-2-E PBM peptide interacts with the PDZ domains of MLLT4, MPP5, and LNX2 with similar binding modes at positions 0 and -2 . The SARS-CoV-2-E PBM is a class II PBM with a hydrophobic residue at position -2 that should contact a hydrophobic residue or the aliphatic part of a lysine at the N-terminal of the $\alpha 2$ helix of the PDZ domain (Songyang et al., 1997; Harris and Lim, 2001). Indeed, the $\mathrm{N}$-terminal of the $\alpha 2$ helix is occupied by a valine (Val 314), a proline (Pro 400), and a glutamine (Gln 1071) in MPP5PDZ, LNX2-PDZ, and MLLT4-PDZ, respectively. A glutamine at this position is different from a canonical class II PDZ but is still classified as a class II PDZ (Figure 3 and Table 1). The side chain of aspartic acid at position -3 is involved in an $\mathrm{H}$-bond with MLLT4-PDZ and MPP5-PDZ, whereas the proline at position -4 does not interact with any of the PDZ domains. Thus, we established the structural basis of SARS-CoV-2-E PBM binding to the PDZ domains of MLLT4, MPP5, and LNX2.

\section{The Viral E Protein Sequestrates PDZ Domains to the Golgi Compartment}

Then we explore the PDZ-PBM interactions between the fulllength E protein and the selected PDZ domains in cells.

Severe acute respiratory syndrome coronavirus 1 or SARSCoV-2 E proteins expressed from cDNA were reported to localize to the endoplasmic reticulum (ER), ERGIC, or the Golgi complex depending on the nature and localization of the tag ( $\mathrm{N}$ or $\mathrm{C}$ ) used in the study (Lopez et al., 2005; Cohen et al., 2011; Pearson et al., 2021). Here, we used the recently developed ALFA tag, that is, small (14 residues) and electroneutral (Götzke et al., 2019) to tag the SARS-CoV-2 E protein at the N-terminal. HeLa cells transiently transfected with SARS-CoV-2 ALFA-E encoding plasmids displayed strong Golgi expression of the viral protein as revealed by the costaining with Golgi marker GM130 (Supplementary Figure 1A).

We then investigated the ability of the viral E protein to recruit GFP-tagged PDZ domains to the Golgi compartment. When transfected alone, GFP-tagged PDZ domains from ZO1, MLLT4, MPP5/PALS1, LNX2, and PARD3 do not accumulate in the Golgi apparatus (Supplementary Figure 1B). Interestingly, all these GFP-tagged PDZ domains relocalize to the Golgi compartment when they are cotransfected with the ALFA-E construct as shown by the GM130 costaining for ZO1 (Figure 4A) and the other PDZ domains (Supplementary Figure 1C). ZO-1 PDZ2/E protein colocalization is strictly PBM dependent as no colocalization is observed between ZO1-PDZ2, and the ALFA E PBM mutant for which the PBM sequence DVLL was substituted by four glycines (Figure 4B). Likewise, this interaction was specific as the SCRIBPDZ1 domain, an unrelated PDZ domain that was not identified in our screen, showed no tropism for the Golgi compartment when it was cotransfected with the ALFA E construct (Figure 4C). These results indicate that the viral E protein can bind to ZO1, MLLT4, MPP5, LNX2, and PARD3 PDZ domains in cellulo in a PBM-specific manner and recruit them to the Golgi apparatus.

\section{The PDZ Domains Bind With Different Affinities With the Original C-Terminal SARS-CoV-2-E PBM and the C-Terminal SARS-CoV-2-E PBM P71L Mutant of the Variant of Concern Beta}

Acquired mutations in SARS-CoV-2 protein E localized close to the PBM were reported, and the most common nonsynonymous mutations were S68F and P71L (Hassan et al., 2020). We focused on the P71L mutation found in the beta variant. The VOC beta was first identified in South Africa in September 2020 and has been reported in more than 130 countries. The mutations on the beta variant make it more transmissible (Tegally et al., 2021), with greater antibody resistance compared with earlier variants of SARS-CoV-2. The 

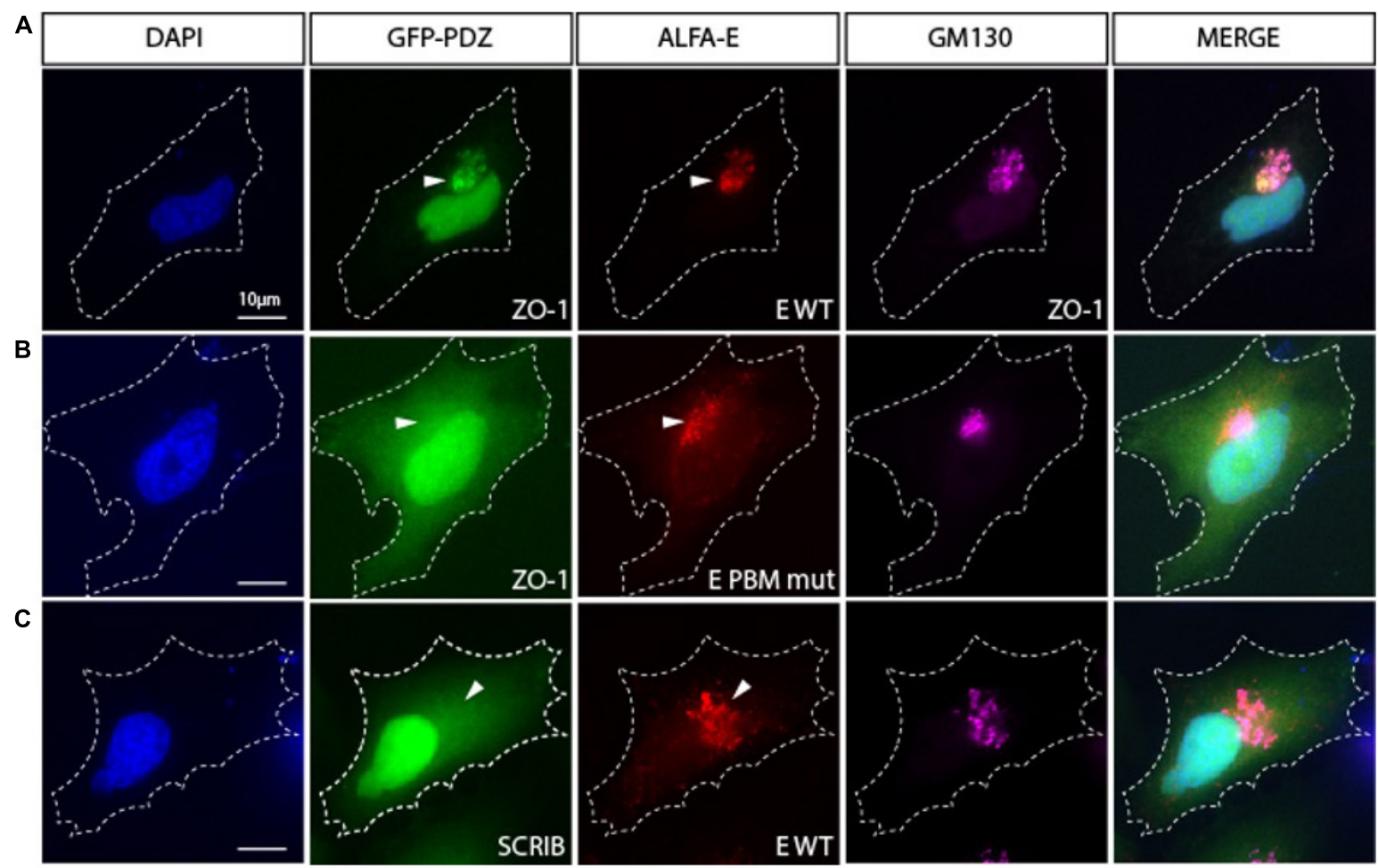

FIGURE 4 | The viral E protein recruits the PDZ domain of ZO1 to the Golgi apparatus. (A) Hela cell cotransfected with encoding constructs GFP-PDZ2 of ZO1 and ALFA-E (red) displays Golgi recruitment of both proteins as indicated by GM130 staining (Magenta). (B) Cotransfection of GFP-ZO1 with ALFA-E PBM mutant (red) does not lead to the recruitment of GFP-ZO1 to the Golgi apparatus. (C) Hela cell cotransfected with GFP-PDZ1 of SCRIB and ALFA-E (red) does not show recruitment of the proteins to the Golgi apparatus (Magenta). White arrowheads indicate Golgi apparatus position. Nuclei are stained with DAPI. Bars correspond to $10 \mu \mathrm{m}$.

TABLE 3 | Kd values between the E protein PBM of SARS-CoV-2 WT and of the P71L mutant for the selected PDZ domains.

\begin{tabular}{|c|c|c|}
\hline & \multicolumn{2}{|c|}{$\mathrm{Kd}(\mu \mathrm{M})$} \\
\hline & SARS-CoV-2 WT & SARS-CoV-2 P71L \\
\hline ZO1 PDZ2 & $15( \pm 11)$ & $133( \pm 28)$ \\
\hline MPP5 PDZ & $30( \pm 24)$ & $22( \pm 2)$ \\
\hline LNX2 PDZ2 & $289( \pm 116)$ & $47( \pm 20)$ \\
\hline PARD3 PDZ3 & $341( \pm 57)$ & No interaction detected \\
\hline MLLT4 PDZ & $569( \pm 129)$ & No interaction detected \\
\hline
\end{tabular}

The data are representative of two independent experiments and error bars correspond to the standard deviation.

beta variant is estimated to be $50 \%$ more infectious than the original coronavirus strain (Tegally et al., 2021) and could be of a higher risk of hospitalization, admission to intensive care, and death (Funk et al., 2021).

The P71L mutation in the $\mathrm{E}$ protein of the beta variant is in the vicinity of the PBM at position -4 . Upstream residues can also affect the PDZ-binding affinity and specificity in addition to the C-terminal positions 0 and -2 of the PBM, which are important for canonical PDZ domain binding (Luck et al., 2012).

We examined the binding affinities of the C-terminal SARSCoV-2-E PBM peptide (12-mers peptide NLNSSRVPDLLV $\mathrm{COOH}_{\text {) }}$ from the original strain and the P71L PBM peptide (12mers peptide sequence NLNSSRVLDLLV $\mathrm{COOH}_{\mathrm{H}}$ ) against the PDZ domains of ZO1, MLLT4, MPP5, LNX2, and PARD3 using microscale thermophoresis (MST) (Table 3 and Supplementary Figure 2). The averaged affinity constants (Kds) of the two PBM peptides for the different PDZ partners are summarized in Table 3. The best affinities for the original SARS-CoV-2 peptide $\mathrm{E}$ are obtained with the PDZ2 of ZO-1 and the PDZ of MPP5 with Kd values of 15 and $30 \mu \mathrm{M}$, respectively. The affinities of SARSCoV-2 peptide E for PARD3-PDZ3 and MLLT4-PDZ are lower with $\mathrm{Kd}$ values of 341 and $569 \mu \mathrm{M}$, respectively. The beta variant P71L mutation does not significantly impact the affinity for the PDZ of MPP5 but considerably reduces the one for the ZO-1PDZ2 with a Kd of $133 \mu \mathrm{M}$, and the PDZ domains of MLLT4 and PARD3 with affinities not detectable in the tested concentration range. Thus, either the P71L mutant does not interact with the PDZs of MLLT4 and PARD3, or the affinities are outside the tested concentration range $(\mathrm{Kd}>1 \mathrm{mM})$.

Conversely, the affinity of LNX2-PDZ2 is improved from 289 to $47 \mu \mathrm{M}$ with the mutant P71L. Thus, this mutation leads to a significant increase in the affinity for LNX2-PDZ2 with a Kd almost six times lower compared with the one of SARS-CoV2 WT.

To resume, significant interactions are detected between the original C-terminal SARS-CoV-2-E PBM peptide and all 
the PDZ domains we tested by MST, in agreement with our previous results using the high-throughput screening holdup assay (Caillet-Saguy et al., 2021). Interestingly, we observed different binding affinities for four over five PDZ domains with the P71L mutant. This strongly suggests a differential specificity profile against the PDZome between the original C-terminal SARS-CoV-2-E PBM and the C-terminal SARS-CoV2-E PBM P71L mutant.

\section{DISCUSSION}

Deletion of protein E strongly reduces the replication of SARS$\mathrm{CoV}-1$ in cells and suppresses virus-induced mortality in mice (DeDiego et al., 2007). The protein E of SARS-CoV-1 contains a C-terminal type II PBM involved in viral pathogenesis (JimenezGuardeño et al., 2014) that binds to PDZ domains of cellular proteins. Interestingly, mice infected with an E PBM mutant virus showed $100 \%$ survival rate, mimicking the phenotype seen with the deletion of the full-length E protein (Jimenez-Guardeño et al., 2014). The protein E from SARS-CoV-2 presents also a PBM like that of SARS-CoV-1, and we recently identified the PDZ proteins targeted by the PBM of SARS-CoV-1, SARSCoV-2, and MERS by screening in vitro the full human PDZ library (Caillet-Saguy et al., 2021). From this previous study and others (Teoh et al., 2010; Toto et al., 2020), we selected five human PDZ-containing proteins expressed in SARS-CoV-2 target cells showing significant interactions with the SARS-CoV2 protein E PBM and involved in cellular junctions and cell polarity: ZO-1/TJP1, PARD3, MLLT4, LNX2, and MPP5/PALS1. Indeed, targeting cellular junctions and polarity machineries is a shared strategy by viruses to facilitate the infectious cycle improving either viral entry, replication, dissemination, or egress. Notably, ZO-1 and PALS1 are targeted by other viruses, such as influenza and SARS-CoV, to disrupt and open TJs to efficiently exit the airway epithelia to spread and disseminate (TorresFlores and Arias, 2015). SARS-CoV-2 was shown to transiently impair bronchial epithelium altering the distribution of $\mathrm{ZO}$ 1 (Robinot et al., 2021), and PALS1 was shown to translocate from TJ to ERGIC when it is targeted by protein $\mathrm{E}$ through its $\mathrm{PBM}$ resulting in the dissociation of TJ in the epithelia of various organs (Chai et al., 2021). In this study, we showed that the five PDZ domains TJP1, PARD3, MLLT4, LNX2, and MPP5/PALS1 interact in a PBM-dependent manner in vitro, and these five PDZ domains colocalize with the full-length $\mathrm{E}$ protein in cellulo sequestrating the PDZ domains into the Golgi compartment. This is consistent with the exposition of the C-terminus of the protein $\mathrm{E}$ to the cytoplasmic side as previously reported (Duart et al., 2020), allowing interactions with viral and host proteins. The mutation P71L of protein E most likely affects the interaction with PDZ domains in cells and the targeting of the Golgi, knowing the affinity changes measured by the MST experiments, in particular, the PDZ of MLLT4 and PARD3 should not be targeted anymore since their affinities are greater than $1 \mathrm{mM}$.

Interestingly, our pull-down experiments showed that the binding partners identified in the holdup screening can interact not only with the last 12 amino acids, as previously shown in the holdup screening, but also with the full-length E protein. We noted a weaker detection of the interaction with the full-length WT protein E compared with the C-terminal peptide because the protein is less expressed, formed oligomers, and the C-terminal peptide is less likely accessible in the context of the entire protein inserted in the membrane (Park et al., 2021). Moreover, we observed by microscopy that the overexpressed protein $\mathrm{E}$ induced a cellular mortality (data not shown). It was previously proposed that the cation channel formed by the overexpressed protein $\mathrm{E}$ could disrupt the host cell membrane (Cao et al., 2021). Less cells are recovered after transfection with WT protein E than with other constructs. To address this issue, we transfected more cells. Interestingly, no cellular toxicity was observed with the GFP-E-GGGG construct. This is in agreement with a previous work on SARS-CoV-1 that showed that the mutant E-GGGG is no longer inducing lethality in mice (Jimenez-Guardeño et al., 2014), illustrating the impact of the E PBM on the homeostasis of infected cells.

Altogether, our results indicate significant interactions between the SARS-CoV-2 WT protein E and the PDZ domains of ZO-1, LNX2, MLLT4, and MPP5. These interactions are dependent on the presence of PBM in the full-length protein E since the mutation of the PBM led to a loss of interaction. PARD3 binds the SARS-CoV-2 E PBM in vitro and colocalizes with the full-length protein E, and not with the mutated PBM E protein that also strongly suggest a specific interaction. We solved the X-ray crystal structures of the complexes between the SARS-CoV-2 E C-terminal encompassing the PBM, and the human LNX2, MLLT4, and MPP5/PALS1 PDZs highlighting the binding modes for three of the potential cellular targets of protein E. We found a swapped dimer in the structure of MLLT4-PDZ with the $\beta 1$ and $\beta 6$ strands swapped (PDB 7QCR). Previous NMR structures of MLLT4PDZ complexed or not with other compounds (peptides or small molecules) only reported monomers (PDB 1XZ9, 2EXG, $1 \mathrm{~T} 2 \mathrm{M}$, and $2 \mathrm{AIN})$. One $\mathrm{X}$-ray structure reported a dimer due to a fusion of a PBM at the C-terminus of MLLT4-PDZ that created a new dimer interface forming an antiparallel $\beta$ sheet between $\beta 2$ strands (PDB 3AXA). To investigate the presence of a dimer in solution, we performed analytical ultracentrifugation (AUC) experiments on MLLT4-PDZ (Table 4 and Supplementary Figure 3). The MLLT4-PDZ is found mainly monomeric in solution with a sedimentation coefficient of $1.4 \mathrm{~S}$, suggesting that the swapped dimer is probably an artifact of crystallization. Interestingly, MLLT4-PDZ is able to recognize type II PBM and also type I PBM due to an unexpected glutamine in the $\alpha 2$ helix as previously reported (Zhou et al., 2005).

Remarkably, ZO-1-PDZ2 forms a very stable swapped dimer with an extended antiparallel inter-domain $\beta$ sheet. The $\beta 1$ and $\beta 2$ strands of one domain is swapped with those from the second domain allowing the formation of the binding groove (Fanning et al., 2007; Chen et al., 2008). We also performed AUC experiments on ZO-1-PDZ2 to verify its oligomeric state in solution (Table 4 and Supplementary Figure 3). We found that ZO-1-PDZ2 adopts two oligomeric 
TABLE 4 | Hydrodynamic parameters of ZO-1 PDZ2 and MLLT4 PDZ derived from the analysis of analytical ultracentrifugation.

\begin{tabular}{|c|c|c|c|c|c|c|}
\hline \multirow[b]{2}{*}{ Sedimentation coefficient (S) } & \multicolumn{3}{|c|}{$\mathrm{ZO}-11 \mathrm{mg} / \mathrm{mL}$} & \multicolumn{3}{|c|}{ MLLT4-PBM 1 mg/mL } \\
\hline & 2.1 & 2.8 & 3.7 & 0.5 & 1.4 & 2.3 \\
\hline Frictional ratio f/fO (average) & & 1.4 & & \multicolumn{3}{|c|}{1.2} \\
\hline Molecular weight estimated by analytical ultracentrifugation (AUC) (kDa) & 26 & 40 & 60 & 2.8 & 12 & 26 \\
\hline Peak proportion\% & 49 & 49 & 2 & 25 & 65 & 10 \\
\hline
\end{tabular}

states in solution: one dimeric form and one higher oligomeric state possibly compatible with a tetramer in solution that might be consistent with a swapped dimer in solution. Conclusively, the X-ray structures have provided the structural basis for SARS-CoV-2-E PBM binding to the PDZ domains of MLLT4, MPP5, and LNX2 and these results offer a mechanistic beginning for SARS-CoV-2 perturbation of PDZcontaining proteins.

Finally, we showed different affinities for the cellular PDZ domains of ZO-1, LNX2, PARD3, MLLT4, and MPP5, with the original SARS-CoV-2 E C-terminal peptide (NLNSSRVPDLLV $_{\mathrm{COOH}}$ ) and the beta variant E C-terminal peptide (-NLNSSRVLDLLV ${ }_{\mathrm{COOH}}$ ) containing the P71L mutation close to the PBM (Figure 1B). This position -4 is not well defined within an electronic density in the crystal structures, and when a density is observed, it is the last upstream residue modeled for the $\mathrm{C}$-terminal of the protein $\mathrm{E}$. In the three complexes we studied, the residue in position -4 is not involved in the interaction network with the PDZ domains. Surprisingly, we determined that P71L mutation markedly altered affinities with host PDZ domains. While it noticeably reduces the affinities for the PDZ domains of ZO-1, MLLT4, and PARD3, it enhances its affinity for LNX2 compared with SARS-CoV-2 WT. Influences of PBM upstream residues on the affinity for PDZ domains have already been reported previously (Lee and Zheng, 2010; Terrien et al., 2012). These findings show that the acquired P71L mutation might have important effects on the human PDZome targeted by the variant during the infection.

Less prevalent than the alpha and delta variants, the beta variant accounted for approximately $10 \%$ of virus samples in France in June 2021. ${ }^{2}$ Mutations in the beta variant make it more transmissible, with greater antibody resistance, higher risk of hospitalization, ICU admission, and death compared with earlier SARS-CoV-2 E variants (Veneti et al., 2021; Wang et al., 2021). In addition to the P71L mutation, the beta variant has other mutations, including three on its spike protein, which may help the virus to escape antibodies and to bind more tightly to human cells (Han et al., 2021). The importance of the P71L mutation in the greater pathogenicity of the beta variant remains to be demonstrated. Nevertheless, because viroporins like E protein are linked to inflammasome activation during viral infection (Schoeman and Fielding, 2019), mutations that can alter the specificity of $\mathrm{E}$ for its protein partners could potentially impact the viral E proinflammatory behavior and, thus, be associated with a change in viral pathogenicity.

\footnotetext{
${ }^{2} \mathrm{https} / /$ www.santepubliquefrance.fr/
}

\section{MATERIALS AND METHODS}

\section{Construct Cloning}

DNA sequences encoding the PDZ domains of ZO-1-2 (PDZ2; residues 184-264), LNX2-2 (PDZ2; residues 334-426), PARDD33 (PDZ3; residues 582-685), MLLT4 (residues 961-1056), and MPP5 (residues 238-336) come from the PDZome library with PDZ domains cloned into a Gateway system (Vincentelli et al., 2015; Duhoo et al., 2019). The PDZ domains were cloned into pETG-41A plasmid vectors as an N-terminal fusion to a histidine tag and a maltose-binding protein (His-MBP-tag). Optimization of expression and purification conditions led us to test other tags for most constructs using the Gateway vector recombination system. Following the protocol of the manufacturer of the Gateway $^{\mathrm{TM}}$ LR Clonase ${ }^{\mathrm{TM}}$ II Enzyme mix (Invitrogen), PDZ domains of ZO-1, LNX2, and PARD3 were subcloned into $\mathrm{pDEST}^{\mathrm{TM}} 17$ vector and MPP5-PDZ into $\mathrm{pDEST}^{\mathrm{TM}} 15$ vector, allowing the production of recombinant proteins as a fusion to an N-terminal histidine and GST tag, respectively. A TEV cleavage site was introduced between the $\mathrm{N}$-terminal tags and the $\mathrm{PDZ}$ sequences.

The pCMV ALFA E vector was constructed as follows: DNA sequence encoding the ALFA tag (MSRLEEELRRRLTE) followed by a linker (GGGGS) fused to the sequence corresponding to the alpha variant of SARS-CoV-2 E cDNA (GenBank: BCM16077.1) synthetized by Eurofins. The ALFA-linker-E sequence was subsequently cloned into a pCMV backbone vector using ClaI and XhoI. The E PBM C-terminal mutation (DVLL > GGGG) was performed using the Q5 site-directed mutagenesis kit (NEB). The sequences corresponding to the PDZ domains were cloned into the pCMV GFP vector using EcoRI and XhoI sites.

\section{Protein Expression and Purification}

The vectors were used to transform E. coli BL21 Star (DE3) (Invitrogen) strain. Bacteria were grown in LB medium supplemented with ampicillin $(100 \mathrm{mg} / \mathrm{L})$ at $37^{\circ} \mathrm{C}$. Protein expression was induced at OD600 nm $0.8-1$ with $0.2 \mathrm{mM}$ IPTG at $18^{\circ} \mathrm{C}$ overnight. Bacteria were then harvested, and PDZ domains of MLLT4, LNX2, PARD3, and MPP5 were resuspended in lysis buffer [Tris $50 \mathrm{mM}(\mathrm{pH}$ 7.5), $\mathrm{NaCl}$ $250 \mathrm{mM}, \beta$-mercaptoethanol $2 \mathrm{mM}$, protease inhibitors, one tablet per $50 \mathrm{~mL}$ of buffer (EDTA-free, Roche Diagnostics), and benzonase (E1014-25KU > $250 \mathrm{U} / \mathrm{L}$ of culture)]. Then the cells were broken under pressure using a cell disruptor CellD (ROQUEMAURE, France) $\left(1.3 \mathrm{kBar}\right.$ at $\left.4^{\circ} \mathrm{C}\right)$. The debris were pelleted by centrifugation $(30,000 \times g, 1 \mathrm{~h}$, $4^{\circ} \mathrm{C}$ ). The GST tag fused proteins were purified by affinity 
chromatography column with GSTrap HP (GE Healthcare) and the His or His-MBP tag fused proteins by nickel-chelated HiTrap Chelating HP (GE Healthcare), followed by a TEV protease cleavage at $16^{\circ} \mathrm{C}$ overnight. A final step of sizeexclusion chromatography was achieved using a Sephacryl S$100 \mathrm{HR}$ 16/600 (GE Healthcare) with a buffer of Tris $50 \mathrm{mM}$ ( $\mathrm{pH}$ 7.5), $\mathrm{NaCl} 150 \mathrm{mM}$, TCEP $0.5 \mathrm{mM}$, protease inhibitors, and one tablet per $100 \mathrm{~mL}$ of buffer (Complete, EDTA 2\%, Roche Diagnostics). Regarding the purification of ZO-1-PDZ2, a denaturation protocol was applied. The bacterial pellet was resuspended in a denaturing solution containing guanidine hydrochloride $(6 \mathrm{M})$ and imidazole $20 \mathrm{mM}$, and cells were lysed by sonication. The debris were pelleted by centrifugation $\left(30,000 \times g, 1 \mathrm{~h}, 4^{\circ} \mathrm{C}\right)$. The His-tagged ZO-1-PDZ2 was purified using a HiTrap Chelating HP (GE Healthcare), where a renaturation gradient by exchange of denaturation buffer to a gel filtration buffer [Tris $50 \mathrm{mM}$ ( $\mathrm{pH} 7.5), \mathrm{NaCl} 150 \mathrm{mM}$, TCEP $0.5 \mathrm{mM}$, protease inhibitors, one tablet per $100 \mathrm{~mL}$ of buffer (Complete, EDTA 2\%, Roche Diagnostics)] was performed. Protein elution was then carried out by a gradient of imidazole from 0 to $500 \mathrm{mM}$ in gel filtration buffer. Finally, a size-exclusion chromatography step was achieved using a Sephacryl ${ }^{\circledR}$ S-200 HR (GE Healthcare).

\section{Peptide Synthesis}

The acetylated peptides containing the C-terminal PBM sequence of $\mathrm{E}$ protein (12 residues long) of SARS-CoV-2 (ac NLNSSRVPDLLV $\mathrm{COOH}_{\text {) }}$ or of its South African mutant P71L (ac NLNSSRVLDLLV $\mathrm{COOH}$ ) were synthesized in a solid phase using the Fmoc strategy (Proteogenix, Schiltigheim, France). Peptides were resuspended in water to prepare stock solutions.

\section{Crystallization, Data Collection, and Structure Determination}

The PDZ-PBM complexes for crystallization were generated by mixing LNX2, MLLT4, or MPP5 PDZ domains with SARS$\mathrm{CoV}-2 \mathrm{E}$ protein $\mathrm{PBM}$ peptide at a ratio of $1: 2$, ensuring that at least $92 \%$ of complexes were formed. Initial screening of crystallization conditions was carried out by the vapor diffusion method using a MosquitoTM nanoliter-dispensing system (TTP Labtech, Melbourn, United Kingdom) following the established protocols (Weber et al., 2019). Sitting drops were set up using $400 \mathrm{nl}$ of a 1:1 mixture of each sample protein and crystallization solutions (672 different commercially available conditions) equilibrated against a $150-\mu 1$ reservoir in multiwell plates (Greiner Bio-one, GmbH, Frichenhausen, Germany). The crystallization plates were stored at $4^{\circ} \mathrm{C}$ in a RockImager $1000^{\circledR}$ (Formulatrix, Bedford, MA, United States) automated imaging system to monitor crystal growth. The best crystals were obtained in crystallization conditions described in Table 2. Crystals were then flash cooled in liquid nitrogen using the condition of crystallization supplemented with $30 \%(\mathrm{~V} / \mathrm{V})$ of glycerol as cryoprotectant.

$\mathrm{X}$-ray diffraction data were collected on the beamlines Proxima-1 and Proxima-2A at Synchrotron SOLEIL (St. Aubin, France). The data were processed by XDS (Kabsch, 2010), and the structures were solved by molecular replacement with PHASER (McCoy, 2007) using the search atomic models PDB id 3AXA, 4UU5, and 5E1Y for MLLT4-PDZ, MPP5-PDZ, and LNX2-PDZ2, respectively. The positions of the bound peptides were determined from an Fo-Fc difference electron density maps. Models were rebuilt using COOT (Emsley et al., 2010), and refinement was done with phenix.refine of the PHENIX suite (Adams et al., 2010). The crystal parameters, data collection statistics, and final refinement statistics are shown in Table 2. The multiple Ramachandran outliers correspond to residues from either the $\mathrm{N}$ - or C-terminal tails of the PDZ domains. More specifically, the outlier residues are Gly 422 (LNX2), Asp 3 (MPP5), and Gly 89 (MLLT4). With respect to the MPP5/E complex, the R/R-free values reported are relatively high due to the presence of a highly mobile/dynamic PDZ domain (chain E). The density for this molecule is very poor, most likely as a consequence of the few contacts established with the other molecules present in the asymmetric unit. The structure factors and coordinates have been deposited in the Protein Data Bank under accession codes 7QCR, 7QCS, and 7QCT for MLLT4-PDZ, MPP5PDZ, and LNX2-PDZ, respectively. All structural figures were generated with the PyMOL Molecular Graphics System, Version (Schrödinger).

\section{Glutathione S-Transferase Pulldown Assay}

N-terminal GST fusion constructs containing the PDZ domains of ZO-1, MPP5, LNX2, PARD3, and MLLT4 were expressed and purified without the cleavage step by TEV protease. Purified GST constructs were individually incubated with glutathione-agarose beads for $1 \mathrm{~h}$ at $4^{\circ} \mathrm{C}$ with mild shaking. The beads were pelleted by centrifugation and washed four times with binding buffer (Tris $50 \mathrm{mM}$ pH 7.5, NaCl $150 \mathrm{mM}$, TCEP $0.5 \mathrm{mM}$, antiprotease with EDTA 2\% 1 tablet/100 mL). HEK 293 cells were transiently transfected with the GFP-tagged constructs using the phosphate calcium method. Cell lysates were prepared by scraping cells in lysis buffer Tris $50 \mathrm{mM}$ pH7.5, triton 2\%, NP40 1\%, NaCl 200 mM with complete protease inhibitor tablet (Roche, Indianapolis, IN, United States), and centrifuged for $10 \mathrm{~min}$ at $13,000 \mathrm{rpm} 4^{\circ} \mathrm{C}$ to pellet cell debris. Soluble detergent extracts were incubated with glutathione resins for $2 \mathrm{~h}$ at $4^{\circ} \mathrm{C}$ prior to washing three times with PBS supplemented with $\mathrm{NaCl} 200 \mathrm{mM}$ and $0.1 \%$ Triton and processed for Western blot analysis with GFP antibody (Novus NB600-313).

\section{Immunofluorescence}

HeLa cells were transfected using the Genejuice transfection reagent (Novagen) according to the protocol of the manufacturer. At $24 \mathrm{~h}$ after transfection, cells were fixed with PBS PFA $4 \%$ for $10 \mathrm{~min}$ and permeabilized in PBS Triton $0.1 \%$ for $5 \mathrm{~min}$ before being processed for immunofluorescence using DAPI, anti-ALFA tag (NanoTag Biotechnologies; cat\#N1502SC3), and anti-GM130 (BD Transduction Lab; cat\#610823). Images were acquired on a Leica DM6B microscope with a $63 \mathrm{X}$ objective. 


\section{Microscale Thermophoresis}

The binding affinities between the C-terminal SARS-CoV-2-E PBM peptide (sequence NLNSSRVPDLLV $\mathrm{COOH}_{\mathrm{H}}$ ) or the P71L PBM peptide (sequence NLNSSRVLDLLV $\mathrm{COOH}$ ) and the PDZ domains of ZO1, MLLT4, MPP5, LNX2, and PARD3 were measured using a Monolith NT.115 instrument (NanoTemper, Gmbh). The purified PDZ domains were covalently labeled using a fluorescent dye reactive on amine following the protocol of the manufacturer (Protein Labelling Kit RED-NHS, Nanotemper). A serial dilution of the WT and the P71L mutant of the E protein PBM peptide was prepared in the buffer containing PBS tween $200.05 \%$. A volume of $10 \mu \mathrm{l}$ of peptide was serially diluted 1:1 in the buffer and mixed with an equal volume of labeled PDZ and loaded on capillaries. The concentration of the various labeled PDZ domains was kept constant, and the peptide concentration varied.

We used $80 \%$ LED and 20\% microscale thermophoresis (MST) power at room temperature and an MST time of $30 \mathrm{~s}$ for all MST measurements. The data analysis and curve fitting with a Kd model were performed with NanoTemper programs MO.Control 2 and MO.Affinity 1 Analysis. The change in the thermophoretic mobility upon titration is measured as a delta of normalized fluorescence. All experiments were made in duplicate.

\section{Analytical Ultracentrifugation}

ZO-1-PDZ2 and MLLT4-PDZ were prepared at $1 \mathrm{mg} / \mathrm{mL}$. MLLT4-PDZ was prepared with an excess of protein E PBM peptide. Samples were prepared in Tris $50 \mathrm{mM} \mathrm{pH} \mathrm{7.5,} \mathrm{NaCl}$ $150 \mathrm{mM}$, and TCEP $0.5 \mathrm{mM}$. A sample of $400 \mu \mathrm{l}$ was loaded into $1.2-\mathrm{cm}$ double-sector cells between two sapphire windows. Cells were incubated for $2 \mathrm{~h}$ at $20^{\circ} \mathrm{C}$ in an AN60-Ti rotor in the Optima-AUC analytical ultracentrifuge (Beckman Coulter) before data acquisition for $15 \mathrm{~h}$ at 42,000 rpm. Sedimentation profiles were monitored over time by absorbance measurement at $280 \mathrm{~nm}$ and by interferometry. The data were analyzed using the continuous size distribution model $c(s)$ of the Sedfit 16.36 software. All distributions were calculated with a floating frictional ratio $\mathrm{f} / \mathrm{f} 0$ and a maximum entropy regularization procedure with a confidence level of 0.68 . The buffer viscosity $(\eta=0.01031$ Poise $)$, the density $(\rho=1.0059)$, and the partial specific volume of 0.746 for MLLT4 and 0.736 for Z0-1 were estimated at $20^{\circ} \mathrm{C}$ from the amino acid sequences at $20^{\circ} \mathrm{C}$ using the software SEDTERP 3.0.3. ${ }^{3}$

\footnotetext{
${ }^{3}$ http://www.jphilo.mailway.com/sednterp.htm
}

\section{REFERENCES}

Adams, P. D., Afonine, P. V., Bunkóczi, G., Chen, V. B., Davis, I. W., Echols, N., et al. (2010). PHENIX: a comprehensive Python-based system for macromolecular structure solution. Acta Crystallogr. D Biol. Crystallogr. 66, 213-221. doi: 10.1107/S0907444909052925

Cabrera-Garcia, D., Bekdash, R., Abbott, G. W., Yazawa, M., and Harrison, N. L. (2021). The envelope protein of SARS-CoV-2 increases intra-Golgi $\mathrm{pH}$ and forms a cation channel that is regulated by pH. J. Physiol. 599, 2851-2868. doi: $10.1113 /$ JP281037

\section{DATA AVAILABILITY STATEMENT}

The datasets presented in this study can be found in online repositories. The names of the repository/repositories and accession number(s) can be found below: http://www.wwpdb. org/, 7QCT; http://www.wwpdb.org/, 7QCR; http://www.wwpdb. org/, 7QCS.

\section{AUTHOR CONTRIBUTIONS}

CC-S designed and directed the project. CC-S and BB conceived and designed the experiments. $\mathrm{YZ}, \mathrm{FA}, \mathrm{AH}, \mathrm{SB}, \mathrm{BN}, \mathrm{BB}$, and CC-S collected the data. YZ, FA, AM, SB, BB, and CC-S analyzed the data. NW and SE-M provided the equipment and funding. CC-S and BB wrote the manuscript with input from the other authors. All authors contributed to the article and approved the submitted version.

\section{FUNDING}

This work was supported by the URGENCE COVID-19 fundraising campaign of Institut Pasteur, the ANR Recherche Action Covid19-FRM PDZCov2 Program, and the DON MICHELIN COVID PFR-5 Cov-2-Cvnet. BB was supported by the Institut National de la Santé et de la Recherche Médicale (INSERM).

\section{ACKNOWLEDGMENTS}

We thank the staff of the Crystallography Core Facility at the Institut Pasteur for carrying out robot-driven crystallization screenings, and the staff at the beamlines of Proxima 1 and Proxima 2 at the French National Synchrotron Facility (SOLEIL, St Aubin, France) for help with data collection. We thank the DIM 1HEALTH region Ile-de-France for funding the Centrifection project that has allowed the Optima ultracentrifuge investment.

\section{SUPPLEMENTARY MATERIAL}

The Supplementary Material for this article can be found online at: https://www.frontiersin.org/articles/10.3389/fmicb. 2022.829094/full\#supplementary-material

Caillet-Saguy, C., Durbesson, F., Rezelj, V. V., Gogl, G., Tran, Q. D., Twizere, J.-C., et al. (2021). Host PDZ-containing proteins targeted by SARS-CoV-2. FEBS J. 2021:15881. doi: $10.1111 /$ febs.15881

Cao, Y., Yang, R., Lee, I., Zhang, W., Sun, J., Wang, W., et al. (2021). Characterization of the SARS-COV -2 E Protein: Sequence, Structure, Viroporin, and Inhibitors. Prot. Sci. 30, 1114-1130. doi: 10.1002/pro.4075

Castaño-Rodriguez, C., Honrubia, J. M., Gutiérrez-Álvarez, J., DeDiego, M. L., Nieto-Torres, J. L., Jimenez-Guardeño, J. M., et al. (2018). Role of Severe Acute Respiratory Syndrome Coronavirus Viroporins E, 3a, and 8a in Replication and Pathogenesis:mBio 9, 17. doi: 10.1128/mBio.02325-17 
Chai, J., Cai, Y., Pang, C., Wang, L., McSweeney, S., Shanklin, J., et al. (2021). Structural basis for SARS-CoV-2 envelope protein recognition of human cell junction protein PALS1. Nat. Commun. 12:3433. doi: 10.1038/s41467-02123533-x

Chen, J., Pan, L., Wei, Z., Zhao, Y., and Zhang, M. (2008). Domain-swapped dimerization of ZO-1 PDZ2 generates specific and regulatory connexin43binding sites. EMBO J. 27, 2113-2123. doi: 10.1038/emboj.2008.138

Chen, Q., Niu, X., Xu, Y., Wu, J., and Shi, Y. (2007). Solution structure and backbone dynamics of the AF-6 PDZ domain/Bcr peptide complex. Protein Sci. 16, 1053-1062. doi: 10.1110/ps.062440607

Chen, X., An, Y., Gao, Y., Guo, L., Rui, L., Xie, H., et al. (2017). Rare Deleterious PARD3 Variants in the aPKC-Binding Region are Implicated in the Pathogenesis of Human Cranial Neural Tube Defects Via Disrupting Apical Tight Junction Formation. Hum. Mutat. 38, 378-389. doi: 10.1002/humu.2 3153

Cohen, J. R., Lin, L. D., and Machamer, C. E. (2011). Identification of a Golgi complex-targeting signal in the cytoplasmic tail of the severe acute respiratory syndrome coronavirus envelope protein. J Virol 85, 5794-5803. doi: 10.1128/ JVI.00060- 11

DeDiego, M. L., Alvarez, E., Almazán, F., Rejas, M. T., Lamirande, E., Roberts, A., et al. (2007). A severe acute respiratory syndrome coronavirus that lacks the $\mathrm{E}$ gene is attenuated in vitro and in vivo. J. Virol. 81, 1701-1713. doi: 10.1128/JVI.01467-06

Duart, G., García-Murria, M. J., Grau, B., Acosta-Cáceres, J. M., MartínezGil, L., and Mingarro, I. (2020). SARS-CoV-2 envelope protein topology in eukaryotic membranes. Open Biol. 10:200209. doi: 10.1098/rsob.20 0209

Duhoo, Y., Girault, V., Turchetto, J., Ramond, L., Durbesson, F., Fourquet, P., et al. (2019). High-Throughput Production of a New Library of Human Single and Tandem PDZ Domains Allows Quantitative PDZ-Peptide Interaction Screening Through High-Throughput Holdup Assay. Methods Mol. Biol. 2025, 439-476. doi: 10.1007/978-1-4939-9624-7_21

Emsley, P., Lohkamp, B., Scott, W. G., and Cowtan, K. (2010). Features and development of Coot. Acta Crystallogr. D Biol. Crystallogr. 66, 486-501. doi: 10.1107/S0907444910007493

Fanning, A. S., Lye, M. F., Anderson, J. M., and Lavie, A. (2007). Domain swapping within PDZ2 is responsible for dimerization of $\mathrm{ZO}$ proteins. J. Biol. Chem. 282, 37710-37716. doi: 10.1074/jbc.M707255200

Fujiwara, Y., Goda, N., Tamashiro, T., Narita, H., Satomura, K., Tenno, T., et al. (2015). Crystal structure of afadin PDZ domain-nectin-3 complex shows the structural plasticity of the ligand-binding site. Protein Sci. 24, 376-385. doi: 10.1002 /pro. 2628

Funk, T., Pharris, A., Spiteri, G., Bundle, N., Melidou, A., Carr, M., et al. (2021). Characteristics of SARS-CoV-2 variants of concern B.1.1.7, B.1.351 or P.1: data from seven EU/EEA countries, weeks 38/2020 to 10/2021. Euro Surveill. 26:2100348. doi: 10.2807/1560-7917.ES.2021.26.16.2100348

Götzke, H., Kilisch, M., Martínez-Carranza, M., Sograte-Idrissi, S., Rajavel, A., Schlichthaerle, T., et al. (2019). The ALFA-tag is a highly versatile tool for nanobody-based bioscience applications. Nat. Commun. 10:4403. doi: 10.1038/ s41467-019-12301-7

Gutiérrez-González, L. H., and Santos-Mendoza, T. (2019). Viral targeting of PDZ polarity proteins in the immune system as a potential evasion mechanism. FASEB J. 33, 10607-10617. doi: 10.1096/fj.201900 $518 \mathrm{R}$

Han, P., Su, C., Zhang, Y., Bai, C., Zheng, A., Qiao, C., et al. (2021). Molecular insights into receptor binding of recent emerging SARS-CoV-2 variants. Nat. Commun. 12:6103. doi: 10.1038/s41467-021-26401-w

Harris, B. Z., and Lim, W. A. (2001). Mechanism and role of PDZ domains in signaling complex assembly. J. Cell Sci. 114, 3219-3231.

Hassan, S. S., Choudhury, P. P., and Roy, B. (2020). SARS-CoV2 envelope protein: non-synonymous mutations and its consequences. Genomics 112, 3890-3892. doi: 10.1016/j.ygeno.2020.07.001

Ikeda, W., Nakanishi, H., Miyoshi, J., Mandai, K., Ishizaki, H., Tanaka, M., et al. (1999). Afadin: a key molecule essential for structural organization of cellcell junctions of polarized epithelia during embryogenesis. J. Cell Biol. 146, 1117-1132. doi: $10.1083 /$ jcb.146.5.1117

Ivanova, M. E., Fletcher, G. C., O’Reilly, N., Purkiss, A. G., Thompson, B. J., and McDonald, N. Q. (2015). Structures of the human Pals1 PDZ domain with and without ligand suggest gated access of Crb to the PDZ peptidebinding groove. Acta Crystallogr. D Biol. Crystallogr. 71, 555-564. doi: 10.1107/ S139900471402776X

James, C. D., and Roberts, S. (2016). Viral Interactions with PDZ DomainContaining Proteins-An Oncogenic Trait? Pathogens 5:5010008. doi: 10.3390/ pathogens5010008

Javier, R. T., and Rice, A. P. (2011). Emerging theme: cellular PDZ proteins as common targets of pathogenic viruses. J. Virol. 85, 11544-11556. doi: 10.1128/ JVI.05410-11

Javorsky, A., Humbert, P. O., and Kvansakul, M. (2021). Structural basis of coronavirus E protein interactions with human PALS1 PDZ domain. Commun. Biol 4:724. doi: 10.1038/s42003-021-02250-7

Jimenez-Guardeño, J. M., Nieto-Torres, J. L., DeDiego, M. L., Regla-Nava, J. A., Fernandez-Delgado, R., Castaño-Rodriguez, C., et al. (2014). The PDZ-binding motif of severe acute respiratory syndrome coronavirus envelope protein is a determinant of viral pathogenesis. PLoS Pathog. 10:e1004320. doi: 10.1371/ journal.ppat.1004320

Jumper, J., Evans, R., Pritzel, A., Green, T., Figurnov, M., Ronneberger, O., et al. (2021). Highly accurate protein structure prediction with AlphaFold. Nature 596, 583-589. doi: 10.1038/s41586-021-03819-2

Kabsch, W. (2010). XDS. Acta Crystallogr. D Biol. Crystallogr. 66, 125-132. doi: $10.1107 /$ S0907444909047337

Lee, H.-J., and Zheng, J. J. (2010). PDZ domains and their binding partners: structure, specificity, and modification. Cell Comm. Sig. 8:8.

Li, Y., Surya, W., Claudine, S., and Torres, J. (2014). Structure of a conserved Golgi complex-targeting signal in coronavirus envelope proteins. J. Biol. Chem. 289, 12535-12549. doi: 10.1074/jbc.M114.560094

Lopez, L. A., Jones, A., Arndt, W. D., Hogue, B. G. (2005). Subcellular localization of sars-cov structural proteins. New York, NY: Springer.

Luck, K., Charbonnier, S., and Travé, G. (2012). The emerging contribution of sequence context to the specificity of protein interactions mediated by PDZ domains. FEBS Lett. 586, 2648-2661. doi: 10.1016/j.febslet.2012.03.056

Mandala, V. S., McKay, M. J., Shcherbakov, A. A., Dregni, A. J., Kolocouris, A., and Hong, M. (2020). Structure and drug binding of the SARS-CoV-2 envelope protein transmembrane domain in lipid bilayers. Nat. Struct. Mol. Biol. 27, 1202-1208. doi: 10.1038/s41594-020-00536-8

McCoy, A. J. (2007). Solving structures of protein complexes by molecular replacement with Phaser. Acta Crystallogr. D Biol. Crystallogr. 63, 32-41. doi: 10.1107/S0907444906045975

Nieto-Torres, J. L., Dediego, M. L., Alvarez, E., Jiménez-Guardeño, J. M., ReglaNava, J. A., Llorente, M., et al. (2011). Subcellular location and topology of severe acute respiratory syndrome coronavirus envelope protein. Virology 415, 69-82. doi: 10.1016/j.virol.2011.03.029

Park, S. H., Siddiqi, H., Castro, D. V., De Angelis, A. A., Oom, A. L., Stoneham, C. A., et al. (2021). Interactions of SARS-CoV-2 envelope protein with amilorides correlate with antiviral activity. PLoS Pathog. 17:e1009519. doi: 10. 1371/journal.ppat.1009519

Pearson, G. J., Broncel, M., Snijders, A. P., and Carlton, J. G. (2021). Exploitation of the Secretory Pathway by SARS-CoV-2 Envelope. bioRxiv doi: 10.1101/2021. 06.30.450614

Robinot, R., Hubert, M., de Melo, G. D., Lazarini, F., Bruel, T., Smith, N., et al. (2021). SARS-CoV-2 infection induces the dedifferentiation of multiciliated cells and impairs mucociliary clearance. Nat. Commun. 12:4354. doi: 10.1038/ s41467-021-24521-x

Roh, M. H., Makarova, O., Liu, C.-J., Shin, K., Lee, S., Laurinec, S., et al. (2002). The Maguk protein, Pals1, functions as an adapter, linking mammalian homologues of Crumbs and Discs Lost. J. Cell Biol. 157, 161-172. doi: 10.1083/jcb.200109010

Schoeman, D., and Fielding, B. C. (2019). Coronavirus envelope protein: current knowledge. Virol. J. 16:69. doi: 10.1186/s12985-019-1182-0

Shepley-McTaggart, A., Sagum, C. A., Oliva, I., Rybakovsky, E., DiGuilio, K., Liang, J., et al. (2021). SARS-CoV-2 Envelope (E) protein interacts with PDZ-domain2 of host tight junction protein ZO1. PLoS One 16:e251955.

Songyang, Z., Fanning, A. S., Fu, C., Xu, J., Marfatia, S. M., Chishti, A. H., et al. (1997). Recognition of unique carboxyl-terminal motifs by distinct PDZ domains. Science 275, 73-77. doi: 10.1126/science.275.5296.73

Tegally, H., Wilkinson, E., Giovanetti, M., Iranzadeh, A., Fonseca, V., Giandhari, J., et al. (2021). Detection of a SARS-CoV-2 variant of concern in South Africa. Nature 592, 438-443. doi: 10.1038/s41586-021-03402-9 
Teoh, K.-T., Siu, Y.-L., Chan, W.-L., Schlüter, M. A., Liu, C.-J., Peiris, J. S. M., et al. (2010). The SARS coronavirus E protein interacts with PALS1 and alters tight junction formation and epithelial morphogenesis. Mol. Biol. Cell 21, 3838-3852. doi: 10.1091/mbc.E10-04-0338

Terrien, E., Chaffotte, A., Lafage, M., Khan, Z., Préhaud, C., Cordier, F., et al. (2012). Interference with the PTEN-MAST2 interaction by a viral protein leads to cellular relocalization of PTEN. Sci. Signal 5:ra58.

Torres-Flores, J. M., and Arias, C. F. (2015). Tight Junctions Go Viral! Viruses 7, 5145-5154. doi: 10.3390/v7092865

Toto, A., Ma, S., Malagrinò, F., Visconti, L., Pagano, L., Stromgaard, K., et al. (2020). Comparing the binding properties of peptides mimicking the Envelope protein of SARS-CoV and SARS-CoV-2 to the PDZ domain of the tight junctionassociated PALS1 protein. Protein Sci. 29, 2038-2042. doi: 10.1002/pro.3936

Veneti, L., Seppälä, E., Larsdatter Storm, M., Valcarcel Salamanca, B., Alnes Buanes, E., Aasand, N., et al. (2021). Increased risk of hospitalisation and intensive care admission associated with reported cases of SARS-CoV-2 variants B.1.1.7 and B.1.351 in Norway, December 2020 -May 2021. PLoS One 16:e258513. doi: 10.1371/journal.pone.0258513

Vincentelli, R., Luck, K., Poirson, J., Polanowska, J., Abdat, J., Blémont, M., et al. (2015). Quantifying domain-ligand affinities and specificities by highthroughput holdup assay. Nat. Methods 12, 787-793. doi: 10.1038/nmeth.3438

Wang, P., Nair, M. S., Liu, L., Iketani, S., Luo, Y., Guo, Y., et al. (2021). Antibody resistance of SARS-CoV-2 variants B.1.351 and B.1.1.7. Nature 593, 130-135. doi: 10.1038/s41586-021-03398-2

Wang, Z., Sandiford, S., Wu, C., and Li, S. S.-C. (2009). Numb regulates cell-cell adhesion and polarity in response to tyrosine kinase signalling. EMBO J. 28, 2360-2373. doi: 10.1038/emboj.2009.190
Weber, P., Pissis, C., Navaza, R., Mechaly, A. E., Saul, F., Alzari, P. M., et al. (2019). High-Throughput Crystallization Pipeline at the Crystallography Core Facility of the Institut Pasteur. Molecules 24:E4451. doi: 10.3390/molecules242 44451

Zhou, H., Xu, Y., Yang, Y., Huang, A., Wu, J., and Shi, Y. (2005). Solution Structure of AF-6 PDZ Domain and Its Interaction with the C-terminal Peptides from Neurexin and Bcr. J. Biol. Chem. 280, 13841-13847. doi: 10.1074/jbc.M411065200

Conflict of Interest: The authors declare that the research was conducted in the absence of any commercial or financial relationships that could be construed as a potential conflict of interest.

Publisher's Note: All claims expressed in this article are solely those of the authors and do not necessarily represent those of their affiliated organizations, or those of the publisher, the editors and the reviewers. Any product that may be evaluated in this article, or claim that may be made by its manufacturer, is not guaranteed or endorsed by the publisher.

Copyright (c) 2022 Zhu, Alvarez, Wolff, Mechaly, Brûlé, Neitthoffer, EtienneManneville, Haouz, Boëda and Caillet-Saguy. This is an open-access article distributed under the terms of the Creative Commons Attribution License (CC BY). The use, distribution or reproduction in other forums is permitted, provided the original author(s) and the copyright owner(s) are credited and that the original publication in this journal is cited, in accordance with accepted academic practice. No use, distribution or reproduction is permitted which does not comply with these terms. 